\title{
Regulation of cytotoxicity and apoptosis-associated pathways contributes to the enhancement of efficacy of cisplatin by baicalein adjuvant in human A549 lung cancer cells
}

\author{
SUPARATA KIARTIVICH ${ }^{1,2^{*}}$, YING WEI ${ }^{1,2^{*}}$, JIAQI LIU ${ }^{1,2}$, RUNGTIP SOIAMPORNKUL $^{3}$, \\ MIHUI LI ${ }^{1,2}$, HONGYING ZHANG ${ }^{1,2}$ and JINGCHENG DONG ${ }^{1,2}$ \\ ${ }^{1}$ Department of Integrative Medicine, Huashan Hospital; ${ }^{2}$ Institutes of Integrative Medicine, \\ Fudan University, Shanghai 200040, P.R. China; ${ }^{3}$ Department of Biochemistry, \\ Faculty of Medicine Siriraj Hospital, Mahidol University, Bangkok 10700, Thailand
}

Received January 29, 2016; Accepted December 16, 2016

DOI: $10.3892 / \mathrm{ol} .2017 .5746$

\begin{abstract}
Scutellaria baicalensis (SB; Chinese name, huangqin) is widely used in Chinese medicine as a traditional adjuvant in the chemotherapy of lung and liver cancer. Baicalein is one of the bioactive flavonoid components isolated from the root of SB. The present study aimed to observe the effect of baicalein, in combination with platin-based systemic chemotherapy (cisplatin), on cytotoxicity and apoptosis of human A549 lung cancer cells. The cell cultures were treated with baicalein, cisplatin, or a combination of the two. Cell viability and cytotoxicity was assayed by XTT, and cell apoptosis was measured by flow cytometry. The apoptosis-associated proteins were detected by western blot analysis. The cytokines in the culture supernatant were detected by ELISA. The present study revealed that cisplatin and the baicalein-cisplatin combination inhibited viability and promoted cytotoxicity of A549 cells. Cisplatin, baicalein and baicalein-cisplatin combination treatments were effective in the promotion of apoptosis of A549 cells. Baicalein and baicalein-cisplatin combination treatments also inhibited B cell lymphoma-2 (Bcl-2) and increased $\mathrm{Bcl}-2$-associated $\mathrm{X}$ protein (Bax) expression. Additionally, cisplatin, baicalein and the baicalein-cisplatin combination promoted caspase-3 expression. Furthermore, the baicalein-cisplatin combination suppressed the secretion of interleukin- 6 , and baicalein and the combination of baicalein cisplatin decreased the secretion of tumor necrosis factor- $\alpha$ of A549 cells. The present study concluded that baicalein
\end{abstract}

Correspondence to: Professor Jingcheng Dong, Institutes of Integrative Medicine, Fudan University, 12 Middle Urumqi Road, Shanghai 200040, P.R. China

E-mail: jcdong2004@126.com

*Contributed equally

Key words: baicalein, cisplatin, cytotoxicity, apoptosis, A549 combined with cisplatin induced cytotoxicity and apoptosis of A549 cells, and such activity may be associated with the regulation of Bcl-2, Bax and caspase-3, indicating a promising alternative method for lung cancer.

\section{Introduction}

Lung cancer is the most common type of cancer and remains the leading cause of cancer-associated mortality in men and women worldwide (1), causing 1.4 million mortalities annually (2). The platin-based systemic chemotherapy (cisplatin) for lung cancer has enhanced the total survival time and life quality of these patients $(3,4)$. Cisplatin was approved by the Food and Drug Administration in 1978 and has been widely used in the treatment of tumors, including testicular, ovarian, head and neck, bladder and small cell lung cancers (5). Accumulating evidence now suggests that cisplatin can generate unrepairable DNA lesions to induce apoptosis of cancer cells (6). However, a large fraction of human malignancies rapidly become insensitive to the cytotoxic effects of cisplatin (5). Therefore, it is important to improve the sensitivity of chemotherapeutic agents in order to reduce drug dosage and improve the efficacy of treatment. Combination medication was recommended to improve the effectiveness of cancer therapy and reduce the side effect of cisplatin (7).

Scutellaria baicalensis (SB), also known as Huang Qin or Chinese skullcap, is used universally as a herbal medicine. In particular, the root decoction is applied to complement lung cancer therapy in modern Chinese medicine $(8,9)$. $\mathrm{SB}$ is currently recognized as a novel anti-cancer drug and chemotherapy adjuvant (10-12). Baicalein is one of the bioactive flavonoid components isolated from the root of $S B$, and it has been revealed to account for the majority of cytotoxicity of SB for a range of cancer cell lines in vitro (13-15). Molecular studies in other human cell lines have demonstrated that these flavonoid compounds possess potent cell cycle arresting and apoptotic properties $(13,16)$. In addition, previous data reported that baicalin, baicalein and wogonin are active inhibitory compounds of SB on human lung cancer cell lines (17). Baicalein, an important bioactive 
flavonoid purified from SB, is one of the most prominent and multi-therapeutic traditional Chinese medicines used in ancient China for the therapeutics of numerous diseases. Baicalein can increase the chemosensitivity of anti-cancer drugs by regulating cell proliferation, apoptosis and the cell cycle, as well as by preventing and attenuating the side effects of chemotherapeutic agents and radiation through the modulation of various targets (18). Over the past decade, numerous studies have demonstrated the potent anti-cancer effects of baicalein in various types of lung malignancies $(19,20)$. The majority of studies focused on the single use of baicalein; however, the pharmacological effects of baicalein-cisplatin combinations remain largely unknown. As apoptosis is a prominent tumor-suppression mechanism, the present study aimed to observe the effect of a combination of baicalein and cisplatin on the cytotoxicity and apoptosis of human A549 lung cancer cells, and to determine whether this combination is effective in reducing the side effects of cisplatin, and improving lung cancer therapy.

\section{Materials and methods}

Drugs, antibodies and reagents. Baicalein (Fig. 1) and cisplatin were purchased from Shanghai Ronghe Corporation (Shanghai, China). The Annexin V-fluorescein isothiocyanate/propidium iodide (Annexin V-FITC/PI) apoptosis detection kit was purchased from BD Biosciences (San Jose, CA, USA). B cell lymphoma-2 (Bcl-2; cat. no. sc-56015), Bcl-2-associated X protein (Bax; cat. no. sc-20067) and caspase-3 (cat. no. sc-65496) antibody were procured from Santa Cruz Biotechnology, Inc. (Dallas, TX, USA). Interleukin (IL)- 6 and tumor necrosis factor (TNF)- $\alpha$ ELISA kits were purchased from R\&D Systems, Inc. (Minneapolis, MN, USA). Cell culture reagents were purchased from Gibco-BRL (Thermo Fisher Scientific, Inc., Waltham, MA, USA). Secondary antibodies and other reagents for western blotting were purchased from GE Healthcare Life Sciences (Chalfont, UK). XTT reagents were purchased from Sigma-Aldrich (Merck Millipore, St. Louis, MO, USA). All cell culture reagents were purchased from HyClone Laboratories (GE Healthcare Life Sciences).

Cell lines and culture. Human lung adenocarcinoma A549 cells were obtained from the Chinese Academy of Sciences, Cell Bank of Type Culture Collection (Shanghai, China). The cells were cultured in Dulbecco's modified Eagle's medium (DMEM, Gibco; Thermo Fisher Scientific, Inc.) supplemented with $10 \%$ fetal bovine serum (FBS) at $37^{\circ} \mathrm{C}$ in a humidified atmosphere with $5 \% \mathrm{CO}_{2}$. A549 cells were grown to $70-80 \%$ confluence in $100 \mathrm{~mm}$ culture plates in a total volume of $10 \mathrm{ml}$ DMEM containing 10\% FBS. Cells were treated with baicalein $(25$ and $50 \mu \mathrm{m})$, or baicalein $(25$ and $50 \mu \mathrm{m})$ combined with cisplatin $(7 \mathrm{mg} / \mathrm{l})$, and were incubated for $24 \mathrm{~h}$.

Cytotoxicity assay. Cell viability and cytotoxicity were evaluated using XTT Cell Proliferation Assay kit (Beyotime Institute of Biotechnology, Haimen, China). Briefly, A549 cells $\left(5 \times 10^{3}\right.$ cell/well $)$ were incubated in 96-well microtiter plates containing $100 \mu \mathrm{l}$ of growth medium. Cells were cultured at $37^{\circ} \mathrm{C}$ in a $\mathrm{CO}_{2}$ incubator for $24 \mathrm{~h}$, and then treated with cisplatin (7 mg/l) and different concentrations (25 and $50 \mu \mathrm{m})$ of baicalein. After $24 \mathrm{~h}$, cultures $(25 \mu \mathrm{l})$ of XTT/PMS solution were added to each well for $2 \mathrm{~h}$. Cell proliferation was measured at $450 \mathrm{~nm}$ using a microplate reader (Bio-Rad Laboratories, Inc., Hercules, CA, USA).

Cell apoptosis assay. Cell apoptosis was detected using the Annexin V-FITC/PI apoptosis detection kit (BD Biosciences, San Jose, CA, USA) as described previously, following the manufacturer's protocol. A549 cells were seeded in culture dishes and incubated for $24 \mathrm{~h}$ with media containing baicalein (25 and $50 \mu \mathrm{m}$ ) and cisplatin $(7 \mathrm{mg} / \mathrm{l})$. Following treatment, cells in each group were collected by trypsin desertion with no EDTA and washed with PBS. Cells were then re-suspended in $500 \mu \mathrm{l}$ binding buffer, $5 \mu \mathrm{l}$ Annexin V-FITC regent and $10 \mu \mathrm{l}$ PI regents, and incubated for $5 \mathrm{~min}$ at room temperature in the dark. Cell apoptosis was detected by flow cytometry (FC500 System; Beckman Coulter, Inc., Brea, CA, USA).

Western blot analysis. A549 cells were seeded onto culture dishes and incubated for $24 \mathrm{~h}$ with media containing baicalein (25 and $50 \mu \mathrm{m}$ ) and cisplatin (7 mg/l). Cultured A549 cells were treated, extracted and total proteins were determined by Pierce BCA Protein Assay kit (Thermo Fisher Scientific, Inc.). Equal amounts of protein were separated by $10 \%$ SDS-PAGE and electrophoretically transferred to polyvinylidene difluoride membranes. The membranes were blocked at room temperature for $1.5 \mathrm{~h}$ with $5 \%(\mathrm{w} / \mathrm{v})$ non-fat milk in TBST buffer (20X TBS Tween-20 buffer; Thermo Fisher Scientific, Inc.) and incubated at $4^{\circ} \mathrm{C}$ overnight with 1:1,000 dilution anti-caspase-3, anti-Bcl-2 and anti-Blc-2-associated $\mathrm{X}$ protein (Bax) antibodies. The membranes were further incubated with 1:5,000 dilution horseradish peroxidase-conjugated secondary antibody (cat. no. NA 933; GE Healthcare Life Sciences). Immunolabeling was detected using an enhanced chemiluminescence kit, using GAPDH as a control. Immunoreactivity was quantified with the Gel Doc 2000 (Bio-Rad Laboratories, Inc.).

Cytokine analysis. To observe the effects of a baicalein-cisplatin combination on inflammatory cytokine secretion of A549 cells, TNF- $\alpha$ and IL-6 levels in A549 cell culture supernatant were measured using enzyme-linked immunosorbent assay kits (R\&D Systems, Inc.), in accordance with the manufacturer's protocol. All samples were assayed in triplicate, and equivocal results were repeated.

Statistical analysis. Experiments presented in the figures were representative of three or more different repetitions. Values were expressed as the mean \pm standard deviation (SD). SPSS 17 software (SPSS, Inc., Chicago, IL, USA) was used to analyze the data. One-way analysis of variance, followed by Fisher's least significant difference test, was employed to determine the statistical significance between different groups. $\mathrm{P}<0.05$ was considered to indicate a statistically significant difference.

\section{Results}

Effects of baicalein-cisplatin combination on cell viability. The results showed that cisplatin, and a combination of 
<smiles>O=c1cc(-c2ccccc2)oc2cc(O)c(O)c(O)c12</smiles>

Chemical formula: $\mathrm{C}_{15} \mathrm{H}_{10} \mathrm{O}_{5}$

Exact mass: 270.05

Molecular weight: 270.24

m/z: 270.05 (100.0\%), 271.06 (16.5\%), $272.06(2.3 \%)$

Elemental analysis: $\mathrm{C}, 66.67 ; \mathrm{H}, 3.73 ; \mathrm{O}, 29.60$

Figure 1. Structure of baicalein; one of the bioactive flavonoid components isolated from the root of Scutellaria baicalensis.

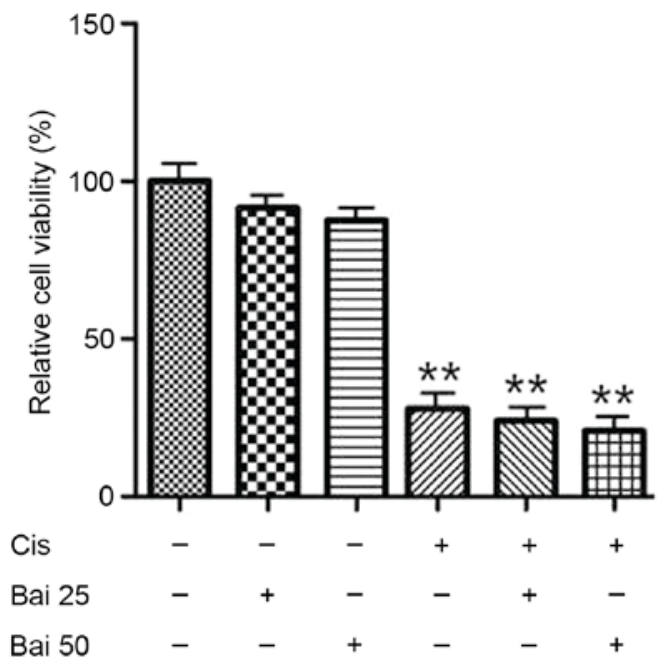

Figure 2. Effects of baicalein combined with cisplatin on A549 cell viability. Results were expressed as percentages of cell survival as compared with the control. Data were presented as the mean \pm standard deviation of three replicate experiments. ${ }^{* *} \mathrm{P}<0.01$ vs. control (non-treated cells). Cis, cisplatin; Bai 25 , baicalein $(25 \mu \mathrm{m})$; Bai 50 , baicalein $(50 \mu \mathrm{m})$

baicalein and cisplatin, inhibited the viability and proliferation of A549 cells compared with the control group $(\mathrm{P}<0.01$; Fig. 2). No significant difference between the cisplatin and baicalein-cisplatin combination groups in reducing the viability and proliferation of A549 cells was observed $(\mathrm{P}>0.05)$.

Effects of baicalein-cisplatin combination on cell apoptosis. Cell apoptosis was evaluated by Annexin V-FITC and PI double fluorescence staining. As demonstrated in Fig. 3, baicalein and cisplatin were effective in increasing the apoptotic rate of A549 cells $(\mathrm{P}<0.05)$. Furthermore, the combination of baicalein and cisplatin also markedly increased the apoptotic rate of A549 cells $(\mathrm{P}<0.01)$, and baicalein $(50 \mu \mathrm{m})$ combined with cisplatin had a more notable increased effect on the rate of apoptosis compared with cisplatin alone $(\mathrm{P}<0.05)$.
Effects of baicalein-cisplatin combination on expression of apoptosis associated proteins. As shown in Fig. 4, baicalein and baicalein-cisplatin combination treatments inhibited the protein expression of $\mathrm{Bcl}-2$, which had the potential to suppress apoptosis $(\mathrm{P}<0.05)$. Furthermore, baicalein $(50 \mu \mathrm{m})$ and baicalein $(50 \mu \mathrm{m})$ combined with cisplatin increased Bax expression $(\mathrm{P}<0.05)$. Meanwhile, cisplatin, baicalein and baicalein combined with cisplatin promoted caspase-3 expression $(\mathrm{P}<0.05)$.

Effects of baicalein-cisplatin combination on TNF- $\alpha$ and IL-6 levels. To elucidate inflammatory cytokines involved in A549 cell apoptosis, the levels of TNF- $\alpha$ and IL- 6 were investigated in cell culture supernatant. The results demonstrated that neither single baicalein nor single cisplatin were effective in inhibiting IL-6 secretion. Baicalein combined with cisplatin showed a significant inhibitory effect on TNF- $\alpha$ and IL-6 levels ( $\mathrm{P}<0.05$; Fig. 5). Baicalein $(25$ and $50 \mu \mathrm{m})$ and a combination of baicalein and cisplatin suppressed $\mathrm{TNF}-\alpha$ secretion of A549 cells ( $\mathrm{P}<0.05$; Fig. 5).

\section{Discussion}

Lung cancer is the leading cause of cancer-associated mortality worldwide, and the 5-year survival for patients with regional lymph node spread shows poor prognosis (21-23). Chemotherapy can enhance the overall survival of patients. However, there are numerous side effects associated with this type of treatment (5). Baicalein has been proposed in several extensive studies as a potential candidate for the treatment of cancer $(14,15,18)$. In the present study, the effect of cisplatin combined with baicalein (a flavonoid component isolated from the root of traditional Chinese medicine SB) on cytotoxicity and apoptosis of human lung cancer cells A549 was examined. Previous data revealed that dysregulated proliferation leading to cellular expansion contributed to the formation of the tissue mass of cancer (24). Results demonstrated that cisplatin and baicalein combined with cisplatin inhibited viability and promoted cytotoxicity of A549 cells. Apoptosis is a process of programmed cell death that occurs in multicellular organisms. The ability of tumor cells to evade engagement in apoptosis can serve a role in their resistance to conventional therapeutic regimens $(25,26)$. Previous studies have demonstrated that baicalein, either alone or in combination baicalin and cisplatin, can exert antitumor activity against different types of cancers $(27,28)$. Cisplatin, baicalin and baicalein-cisplatin combination treatments promoted the apoptosis of A549 cells. Furthermore, the baicalein-cisplatin combination treatment was more effective in the promotion of apoptosis, indicating an improvement in the efficacy of chemotherapy by baicalein adjuvant. This was in accordance with previous studies that demonstrated that baicalein can increase the chemosensitivity of anticancer drugs by regulating cell proliferation and apoptosis $(25,26)$.

Apoptosis serves a pivotal role in the pathogenesis of cancer, and the mechanism of apoptosis is complex and involves a number of pathways. Apoptosis is a popular target for numerous treatment strategies. Caspases are activated in response to diverse cell death stimuli and ultimately dismantle the cell through restricted proteolysis of numerous 
A

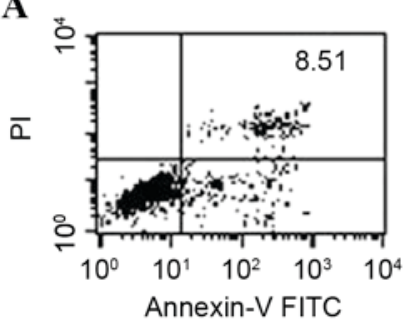

D



B

$\bar{\alpha}$

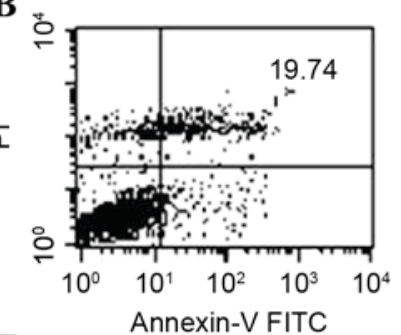

E

$\bar{\alpha}$

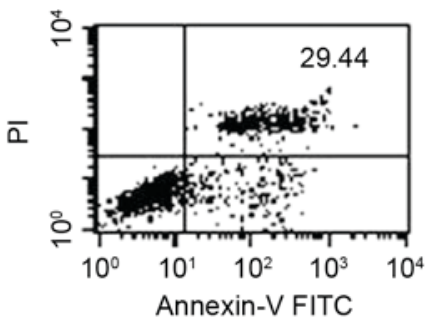

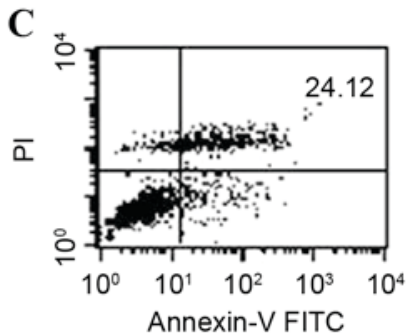

F

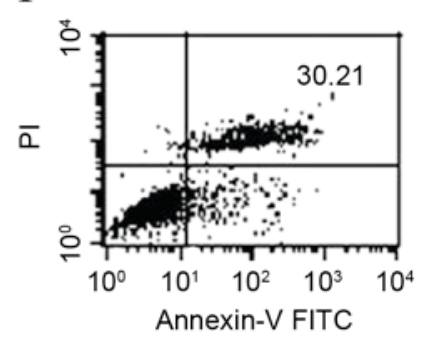

G

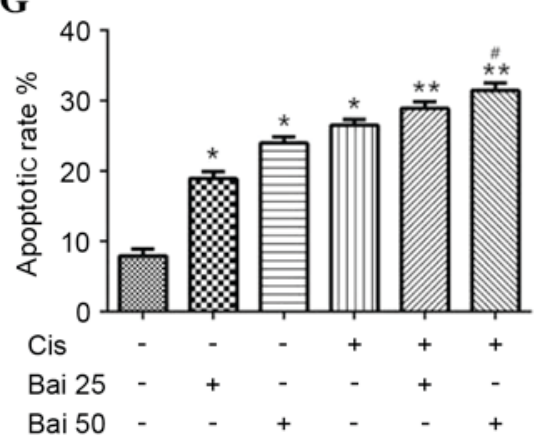

Figure 3. Effects of a baicalein-cisplatin combination treatment on cell apoptosis. Cells were analyzed using Annexin V/PI staining. Effects of (A) control, (B) baicalein $(25 \mu \mathrm{m}),(\mathrm{C})$ baicalein $(50 \mu \mathrm{m})$, (D) cisplatin, (E) baicalein $(25 \mu \mathrm{m})$ and cisplatin, (F) baicalein $(50 \mu \mathrm{m})$ and cisplatin treatment on cell apoptosis. (G) Effect of treatment with combined baicalein and cisplatin on the rate of cellular apoptosis. Data were presented as the mean \pm standard deviation of three replicate experiments. ${ }^{*} \mathrm{P}<0.05$ vs. controls (non-treated cells); ${ }^{* * *} \mathrm{P}<0.01$ vs. control (non-treated cells); ${ }^{*} \mathrm{P}<0.05$ vs. cisplatin. PI, propidium iodide; Cis, cisplatin; Bai 25, baicalein $(25 \mu \mathrm{m})$; Bai 50, baicalein $(50 \mu \mathrm{m})$; FITC, fluorescein isothiocyanate.

cellular proteins (27). Caspases are central to the mechanism of apoptosis as they are the initiators as well as the executioners (28). Caspase-3 appears to be the major executioner caspase during the demolition phase of apoptosis (27). Furthermore, caspase- 3 can cleave the inhibitor of the caspase-activated deoxyribonuclease, which is responsible for nuclear apoptosis (29). Data in the present study demonstrated that cisplatin, baicalein and baicalein combined with cisplatin increased caspase- 3 expression, indicating their role in the promotion of apoptosis of A549 cells. The Bcl-2 family can regulate the apoptosis pathway in a variety of cell types. There are two main groups of Bcl-2 proteins, Bcl-2 and Bax. $\mathrm{Bcl}-2$, an anti-apoptotic protein, is an oncogene that inhibits radiation- or chemotherapy-induced apoptosis (30). Cervical cancers with Bcl-2 expression have been reported to exhibit radiation resistance and poor prognosis $(31,32)$. Bax is a member of the Bcl-2 family and serves a role in enhancing apoptosis (33). In cervical cancer patients treated by radiotherapy alone, patients with Bax-positive tumors have been demonstrated to exhibit a higher sensitivity to radiotherapy compared with those with Bax tumors. The balance between the pro- and anti-apoptotic proteins determines whether apoptosis is initiated. Previous studies demonstrated that the use of Bcl-2 specific small interfering RNA specifically inhibits the expression of the target gene in vitro and in vivo, with anti-proliferative and pro-apoptotic effects observed in pancreatic carcinoma cells (34). Results of the present study revealed that baicalein and baicalein-cisplatin combination treatments inhibited anti-apoptotic protein Bcl-2 expression. Baicalein and baicalein combined with cisplatin increased the pro-apoptotic protein Bax expression, indicating their potential to induce apoptosis of A549 cells.

TNF- $\alpha$ was considered a critical pro-inflammatory cytokine in tumors, and increasing evidence suggested that TNF- $\alpha$ may act as an endogenous tumor promoter $(35,36)$. Results of the present study demonstrated a significant decrease $(\mathrm{P}<0.05)$ in TNF- $\alpha$ level by baicalein and baicalein-cisplatin combination treatments. According to previous studies, cancer cells overexpress IL-6 in the tumor microenvironment $(37,38)$. Patients suffering from various cancers, including non-small cell lung cancer, had increased levels of IL-6 in serum samples $(39,40)$. Increasing data showed that IL-6 served a key role in molecular abnormality, chemoresistance, epithelial to mesenchymal transition and stem cell formation in various types of malignant states (41). Previous studies have reported that IL-6 was also associated with colorectal cancer pathogenesis and metastasis (42). In the present study, treatment with a baicalein-cisplatin combination reduced the IL-6 level in 
A

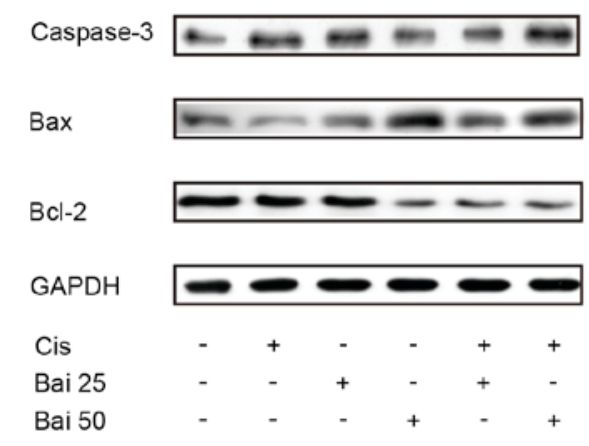

C

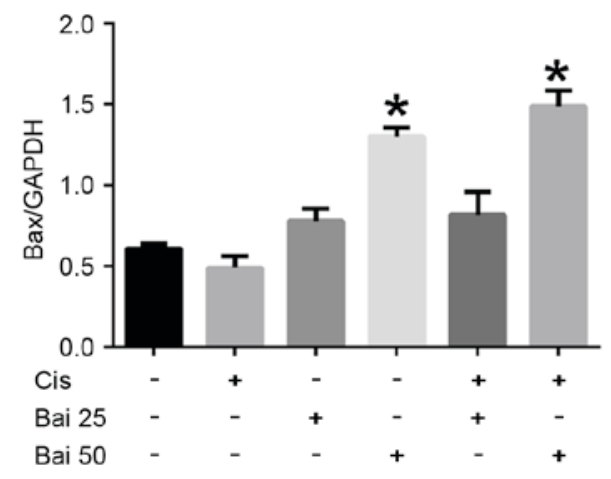

B

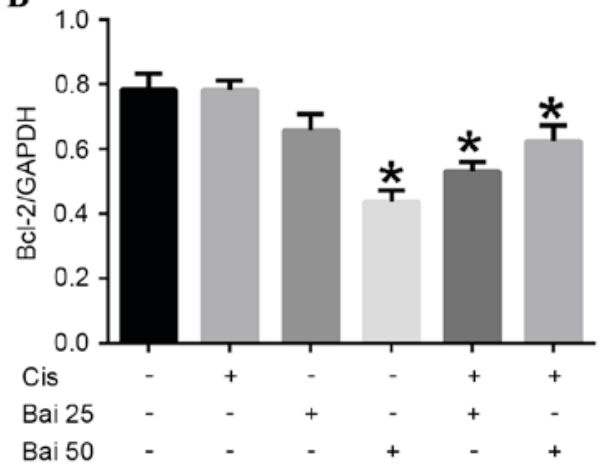

D

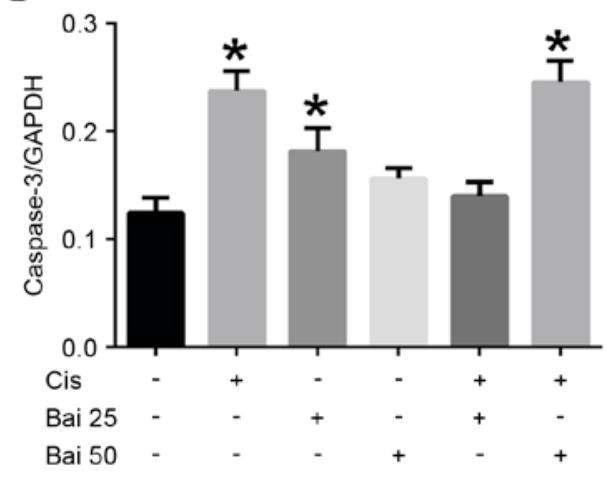

Figure 4. Effects of baicalein combined with cisplatin on A549 cell apoptosis-associated protein expression. The protein expression of Bcl-2, Bax and caspase-3 in each group was analyzed by western blot analysis. (A) Effects of baicalein combined with cisplatin on caspase 3, Bax and Bcl-2 protein expression. Effects of baicalein combined with cisplatin on (B) Bcl-2, (C) Bax and (D) caspase 3 protein expression. Data were presented as the mean \pm standard deviation of three replicate experiments. "P<0.05 vs. control (non-treated cells); Cis, cisplatin; Bai 25, baicalein (25 $\mu \mathrm{m})$; Bai 50, baicalein (50 $\mu$ m); Bcl-2, B cell lymphoma-2; Bax, Bcl-2-associated X protein.

A



B

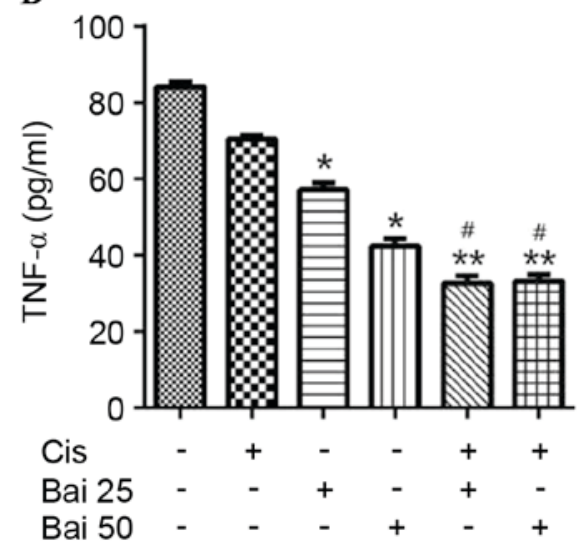

Figure 5. Effects of baicalein combined with cisplatin on TNF- $\alpha$ and IL-6 levels. (A) IL-6 and (B) TNF- $\alpha$ levels in culture supernatant were measured by ELISA. Data were presented as the mean \pm standard deviation of three replicate experiments. ${ }^{*} \mathrm{P}<0.05$ vs. control (non-treated cells); ${ }^{* *} \mathrm{P}<0.01$ vs. control (non-treated cells); ${ }^{\#} \mathrm{P}<0.05$ vs. cisplatin. Cis, cisplatin; Bai 25, baicalein $(25 \mu \mathrm{m})$; Bai 50, baicalein (50 $\left.\mu \mathrm{m}\right)$; TNF- $\alpha$, tumor necrosis factor- $\alpha$; IL-6, interleukin-6.

culture supernatant, indicating the possible suppressive effect on A549 cell.

In conclusion, the present study demonstrated that baicalein combined with cisplatin induces cytotoxicity and apoptosis of A549 cells, and such activity may be associated with regulation of Bcl-2, Bax and caspase-3. This indicates a promising alternative method for lung cancer.

\section{Acknowledgements}

The present study was supported by the National Natural Science Program of China (grant nos. 81173390, 81403476 and 81573758) and the Development Project of Shanghai Peak Disciplines-Integrated Chinese and Western Medicine. 


\section{References}

1. Zhou C and Yao LD: Strategies to improve outcomes of patients with EGRF-mutant non-small cell lung cancer: Review of the literature. J Thorac Oncol 11: 174-186, 2016.

2. Tan CS, Cho BC and Soo RA: Next-generation epidermal growth factor receptor tyrosine kinase inhibitors in epidermal growth factor receptor -mutant non-small cell lung cancer. Lung Cancer 93: 59-68, 2016.

3. Tian Y, Zhang J, Yan S, Qiu L and Li Z: FATS expression is associated with cisplatin sensitivity in non small cell lung cancer. Lung Cancer 76: 416-422, 2012.

4. Lee SW, Song GS, Kwon CH and Kim YK: Beneficial effect of flavonoid baicalein in cisplatin-induced cell death of human glioma cells. Neurosci Lett 382: 71-75, 2005.

5. Galluzzi L, Vitale I, Michels J, Brenner C, Szabadkai G, Harel-Bellan A, Castedo M and Kroemer G: Systems biology of cisplatin resistance: Past, present and future. Cell Death Dis 5 e1257, 2014.

6. Dasari S and Tchounwou PB: Cisplatin in cancer therapy: Molecular mechanisms of action. Eur J Pharmacol 740: 364-378, 2014

7. Song W, Tang Z, Li M, Lv S, Sun H, Deng M, Liu H and Chen X: Polypeptide-based combination of paclitaxel and cisplatin for enhanced chemotherapy efficacy and reduced side-effects. Acta Biomater 10: 1392-1402, 2014.

8. Kumagai T, Muller CI, Desmond JC, Imai Y, Heber D and Koeffler HP: Scutellaria baicalensis, a herbal medicine: Anti-proliferative and apoptotic activity against acute lymphocytic leukemia, lymphoma and myeloma cell lines. Leuk Res 31: 523-530, 2007.

9. Gao J, Morgan WA, Sanchez-Medina A and Corcoran O: The ethanol extract of Scutellaria baicalensis and the active compounds induce cell cycle arrest and apoptosis including upregulation of p53 and Bax in human lung cancer cells. Toxico Appl Pharmacol 254: 221-228, 2011.

10. Park KI, Park HS, Kang SR, Nagappan A, Lee DH, Kim JA Han DY and Kim GS: Korean Scutellaria baicalensis water extract inhibits cell cycle G1/S transition by suppressing cyclin D1 expression and matrix-metalloproteinase-2 activity in human lung cancer cells. J Ethnopharmacol 133: 634-641, 2011.

11. Gol'dberg VE, Ryzhakov VM, Matiash MG, Stepovaia EA, Boldyshev DA, Litvinenko VI and Dygă̌ AM: Dry extract of Scutellaria baicalensis as a hemostimulant in antineoplastic chemotherapy in patents with lung cancer. Eksp Klin Farmakol 60: 28-30, 1997.

12. Gao J, Zhao H, Hylands PJ and Corcoran O: Secondary metabolite mapping identifies Scutellaria inhibitors of human lung cancer cells. J Pharm Biomed Anal 53: 723-728, 2010.

13. Gong WY, Wu JF, Liu BJ, Zhang HY, Cao YX, Sun J, Lv YB, Wu X and Dong JC: Flavonoid components in Scutellaria baicalensis inhibit nicotine-induced proliferation, metastasis and lung cancer-associated inflammation in vitro. Int J Oncol 44: 1561-1570, 2014.

14. Sahu BD, Mahesh Kumar J and Sistla R: Baicalein, a bioflavonoid, prevents cisplatin-induced acute kidney injury by up-regulating antioxidant defenses and down-regulating the MAPKs and NF-kappaB pathways. PLoS One 10: e0134139, 2015.

15. Zhang Y, Song L, Cai L, Wei R, Hu H and Jin W: Effects of baicalein on apoptosis, cell cycle arrest, migration and invasion of osteosarcoma cells. Food Chem Toxicol 53: 325-333, 2013.

16. Li-Weber M: New therapeutic aspects of flavones: The anticancer properties of Scutellaria and its main active constituents Wogonin, Baicalein and Baicalin. Cancer Treat Rev 35: 57-68, 2009.

17. Li-Weber M: Targeting apoptosis pathways in cancer by Chinese medicine. Cancer Lett 332: 304-312, 2013.

18. Takahashi H, Chen MC, Pham H, Angst E, King JC, Park J, Brovman EY, Ishiguro H, Harris DM, Reber HA, et al: Baicalein, a component of Scutellaria baicalensis, induces apoptosis by Mcl-1 down-regulation in human pancreatic cancer cells. Biochim Biophys Acta 1813: 1465-1474, 2011.

19. Cathcart MC, Useckaite Z, Drakeford C, Semik V, Lysaght J, Gately K, O'Byrne KJ and Pidgeon GP: Anti-cancer effects of baicalein in non-small cell lung cancer in-vitro and in-vivo. BMC Cancer 16: 707, 2016.
20. Shi Y, Cheng L, Gao X, Na J, Xiang K, Jiang X, Liu J, Wu Y, Xia Y, Sun X, et al: The effect of Baicalein against lung cancer depends on GADD45a down-regulation. Int J Clin Exp Med 9: 1458-1468, 2016.

21. Kato T, Wada H, Patel P, Hu HP, Lee D, Ujiie H, Hirohashi K, Nakajima T, Sato M, Kaji M, et al: Overexpression of KIF23 predicts clinical outcome in primary lung cancer patients. Lung Cancer 92: 53-61, 2016.

22. Greenlee RT, Hill-Harmon MB, Murray T and Thun M: Cancer statistics, 2001. CA Cancer J Clin 51: 15-36, 2001.

23. National Cancer Institute: Lung and Bronchus Cancer, 2012. http://seer.cancer.gov/statfacts/html/lungb.html.

24. Garay T, Juhász E, Molnár E, Eisenbauer M, Czirók A, Dekan B, László V, Hoda MA, Döme B, Tímár J, et al: Cell migration or cytokinesis and proliferation?-revisiting the 'go or grow' hypothesis in cancer cells in vitro. Exp Cell Res 319: 3094-3103, 2013.

25. Kasibhatla S and Tseng B: Why target apoptosis in cancer treatment? Mol Cancer Ther 2: 573-580, 2003

26. Mohammad RM, Muqbil I, Lowe L, Yedjou C, Hsu HY, Lin LT, Siegelin MD, Fimognari C, Kumar NB, Dou QP, et al: Broad targeting of resistance to apoptosis in cancer. Semin Cancer Biol 35 (Suppl): S78-S103, 2015.

27. Walsh JG, Cullen SP, Sheridan C, Luthi AU, Gerner C and Martin SJ: Executioner caspase-3 and caspase-7 are functionally distinct proteases. Proc Natl Acad Sci USA 105: 12815-12819, 2008.

28. Wong RS: Apoptosis in cancer: From pathogenesis to treatment. J Exp Clin Cancer Res 30: 87, 2011.

29. Ghobrial IM, Witzig TE and Adjei AA: Targeting apoptosis pathways in cancer therapy. CA Cancer J Clin 55: 178-194, 2005.

30. Belka C and Budach W: Anti-apoptotic Bcl-2 proteins: Structure, function and relevance for radiation biology. Int J Radiat Biol 78: 643-658, 2002.

31. Kato R, Hasegawa K, Torii Y, Udagawa Y and Fukasawa I: Factors affecting platinum sensitivity in cervical cancer. Oncol Lett 10: 3591-3598, 2015.

32. Sultana H, Kigawa J, Kanamori Y, Itamochi H, Oishi T, Sato S, Kamazawa S, Ohwada M, Suzuki M and Terakawa N: Chemosensitivity and p53-Bax pathway-mediated apoptosis in patients with uterine cervical cancer. Ann Oncol 14: 214-219, 2003.

33. Brady HJ and Gil-Gómez G: Bax. The pro-apoptotic Bcl-2 family member, Bax. Int J Biochem Cell Biol 30: 647-650, 1998.

34. Ocker M, Neureiter D, Lueders M, Zopf S, Ganslmayer M, Hahn EG, Herold C and Schuppan D: Variants of bcl-2 specific siRNA for silencing antiapoptotic bcl-2 in pancreatic cancer. Gut 54: 1298-1308, 2005.

35. Balkwill F: Tumor necrosis factor or tumor promoting factor? Cytokine Growth Factor Rev 13: 135-141, 2002.

36. Bodduluru LN, Kasala ER, Barua CC, Karnam KC, Dahiya V and Ellutla M: Antiproliferative and antioxidant potential of hesperetin against benzo(a)pyrene-induced lung carcinogenesis in Swiss albino mice. Chem Biol Interact 242: 345-352, 2015.

37. Middleton K, Jones J, Lwin Z and Coward JI: Interleukin-6: An angiogenic target in solid tumours. Crit Rev Oncol Hematol 89: 129-139, 2014.

38. Cohen S, Bruchim I, Graiver D, Evron Z, Oron-Karni V, Pasmanik-Chor M, Eitan R, Bernheim J, Levavi H, Fishman A and Flescher E: Platinum-resistance in ovarian cancer cells is mediated by IL- 6 secretion via the increased expression of its target cIAP-2. J Mol Med (Berl) 91: 357-368, 2013.

39. Nguyen DP, Li J and Tewari AK: Inflammation and prostate cancer: The role of interleukin 6 (IL-6). BJU Int 113: 986-992, 2014.

40. Guo Y, Xu F, Lu T, Duan Z and Zhang Z: Interleukin-6 signaling pathway in targeted therapy for cancer. Cancer Treat Rev 38: 904-910, 2012.

41. Bharti R, Dey G and Mandal M: Cancer development, chemoresistance, epithelial to mesenchymal transition and stem cells: A snapshot of IL-6 mediated involvement. Cancer Lett 375: 51-61, 2016.

42. Yeh KY, Wu TH and Wu TL: Colorectal cancer cell-derived interleukin- 6 enhances the phagocytic capacity and migration of THP-1 cells. Cytokine 79: 82-89, 2016. 